\title{
Correspondence
}

\section{Ethical issues of a doctors' strike}

SIR

The two recent papers on the ethical aspects of a doctors' strike in this journal $(1,2)$ were timely for us in New Zealand where the junior doctors have been considering 'industrial action' for some time. Both papers, however, fell short on key arguments. Brecher (1), although convincing in his argument on the relative material valuation of life, largely skirted the issue of the special nature of the physician-patient contract and the entailed moral obligations. Grosskopf et al (2) were almost apologetic in their article although the Israeli doctors had such a strong case for a strike, were acutely aware of their ethical responsibilities and had a broader perspective of the doctorpatient contract. I think the key questions in the ethical debate on a strike by doctors are: a) Can the longterm benefits to the doctors and the public offset the short-term costs to the latter, including avoidable death? b) Can immediate needs be set aside in anticipation of future benefit? c) Does the nature of the physician-patient or physician-society contract preclude strike action? and d) How would a strike affect the public image of doctors?

In the public health system, situations can arise when the working conditions of the doctors are so bad that a strike becomes understandable. Does that also make it morally conscionable? Even if life is measured in relative terms, a moral justification for a strike exists only if the long-term benefits to the physicians and their families are great, the health-care delivery improves considerably as a result, more lives are possibly saved in the long run and the benefits are passed on to the physicianless members of the society (3). Less stringent criteria need to be applied if a case can be made that doctors are being exploited, something more likely to happen to junior doctors (4) or in socialised medicine (1). Some moral dilemmas can be bypassed by limiting a strike so that emergency care does not suffer and it merely results in the prolongation of waiting lists already existing because of inadequate facilities.

The central argument, however, is the nature of the physician-patient contract. A doctor has a special contract with an individual patient $\mathrm{s} / \mathrm{he}$ accepts for treatment and is morally bound to provide continuing care or transfer to another competent physician. The doctor cannot be said to have a special obligation towards individuals who might become his patients in the future were $s / h e$ to continue practising medicine, or never to be absent from work or fall ill or cancel an appointment for any other reason. $S /$ he has a contract with society to act responsibly when s/ he 'is there' but is not bound to be always available 'under any circumstances'. Moreover, in countries where medicine is largely socialised, the provision of health care is the joint responsibility of the physician, the hospital and the government. The contract, therefore, has multiple arms. If, for example, the hospital fails to meet its contract with the physician, the sanctity of the other limbs of the contract suffers. Furthermore, as doctors change from healers to technocrats and the doctor-patient relationship becomes less paternalistic with patients becoming more litigious and doctors more defensive, the nature of the contract will be further altered. It is clear that this concept of the physician-patient contract makes strike action ethically more justifiable.

Provided doctors are reasonable in their demands, a strike can only make them seem human! Little harm can accrue from shattering a somewhat antiquated myth of sainthood and injecting a good dose of realism (3).

\section{References}

(1) Brecher R. Striking responsibilities. Fournal of medical ethics 1985; 11 : 66-69.

(2) Grosskopf I, Buckman G, Garty M. Ethical dilemmas of the doctors' strike in Israel. Fournal of medical ethics 1985; 11: 70-71.

(3) Veatch $R M$. Interns and residents on strike: commentary. The Hastings Center report 1975; 5(6): 79.

(4) Anonymous. Hours 'justify overtime pay'. Otago Daily Times 1985 Sept 4: 5 (cols 8-10).

P S SACHDEV MD, MRANZCP Department of Psychological Medicine, University of Otago, Dunedin, New Zealand

[See also pages 40-44. Editor]

\section{Acts and omissions doctrine and abortion: reply to Dr Toon}

SIR

Dr Toon (1) rightly points out that tradition asserts a difference between actively killing and letting die. In certain instances it seems permissible to let die because of the inabilities of physicians, for example, to treat certain conditions. One wonders therefore if the precarious conditions of 'persons' at risk for spontaneous abortion would similarly legitimise letting them die.

First of all, it seems to me that this distinction does little to explain why persons subject to spontaneous abortion are systematically excluded from the benefits of medical research and practice. On the face of it, it seems that we would have as much obligation to 